\title{
Computer applications for avalanche forecasting in the United States
}

\author{
BRUCE TREMPER \\ Utah Avalanche Forecast Center, 337 North 2370 West, Salt Lake City, UT 84116, U.S.A. \\ RAND DECKER \\ Department of Civil Engineering, 3220 Merill Engineering Bldg., University of Utah, Salt Lake City, UT 84112, U.S.A.
}

\begin{abstract}
Avalanche hazard forecasters must evaluate a number of different important parameters which often vary markedly over time and distance. Computer applications have been developed to help the avalanche forecaster manage the complex data. These include programs which simply graph and tabulate data into easily ingested displays, database and statistical software, deterministic models of the snowpack evolution and stability, and finally, networks of avalanche information. This paper is an overview of computer software currently available in English and in use in the United States.
\end{abstract}

\section{INTRODUCTION}

Avalanche forecasters face a particularly difficult problem. First, a number of different parameters contribute towards snowpack instability; second, the effects of many of the parameters counteract each other; and third, most of the parameters vary markedly over both time and distance. With the advent of powerful, portable, personal computers many programs have been written to help take the guesswork out of avalanche forecasting.

The software ranges from relatively simple graphical displays of the important variables, to more complex database programs, to very sophisticated deterministic models which simulate snowpack structure as well as snow stability itself.

This paper is a brief overview of available and commonly used computer software written for an English-speaking user in the United States. Many of these programs emulate similar software originally developed in Europe, and references to those European authors appear in this paper where appropriate. Consequently, this paper is certainly not an exhaustive overview of all programs, but only those known to the authors to be commonly used in the United States. This paper also discusses the advantages and disadvantages of these programs, the sources and prices, and discusses future directions of computer software for avalanche forecasting.

Unless otherwise noted, all the software discussed in this paper was written in English for a DOS operating system, to run on an IBM-compatible computer.

\section{SNOW-PIT PROGRAMS}

The time-honored method of determining the structure of the snowpack is to dig a snow pit and examine the various layers. Because the human brain has a limited capacity to understand raw numbers, most workers find it useful to graph the data to yield an easily ingested visual display. For instance snow hardness, density, crystal type and temperature especially lend themselves to graphical displays. An effective graph can, at a glance, reveal the structure and composition of the snowpack, the snowpack history, and often, the present and future stability of the snowpack.

\section{Peter Weir snow-pit program}

The most sophisticated and powerful snow pit program was written by P. Weir with the Ministry of Highways in Canada. It runs under the operating system Windows 3.1. The choice of snow crystals conforms to the International Classification of Snow on the Ground (Colbeck and others, 1990) and it also plots the snow-pit profile in the standard international format. The program offers dropdown menus on nearly every parameter, allowing the user to choose the appropriate value easily. The program accepts the parameters of snow type (and subclass), snow hardness, moisture, temperature, density, and crystal size, and it plots the standard international symbol for each (Fig. 1).

\section{Dan Judd snow-pit program}

Other snow-pit programs are older and do not conform to the International Standard. One such program was written by D. Judd, a Utah Department of Transportation avalanche forecaster. He wrote the program in Pascal and included a menu-driven user interface. Like Weir's program, Judd's program stores the data for each snow pit in a separate file so it can easily be transferred over a 
Tremper and Decker: Computer applications for avalanche forecasting

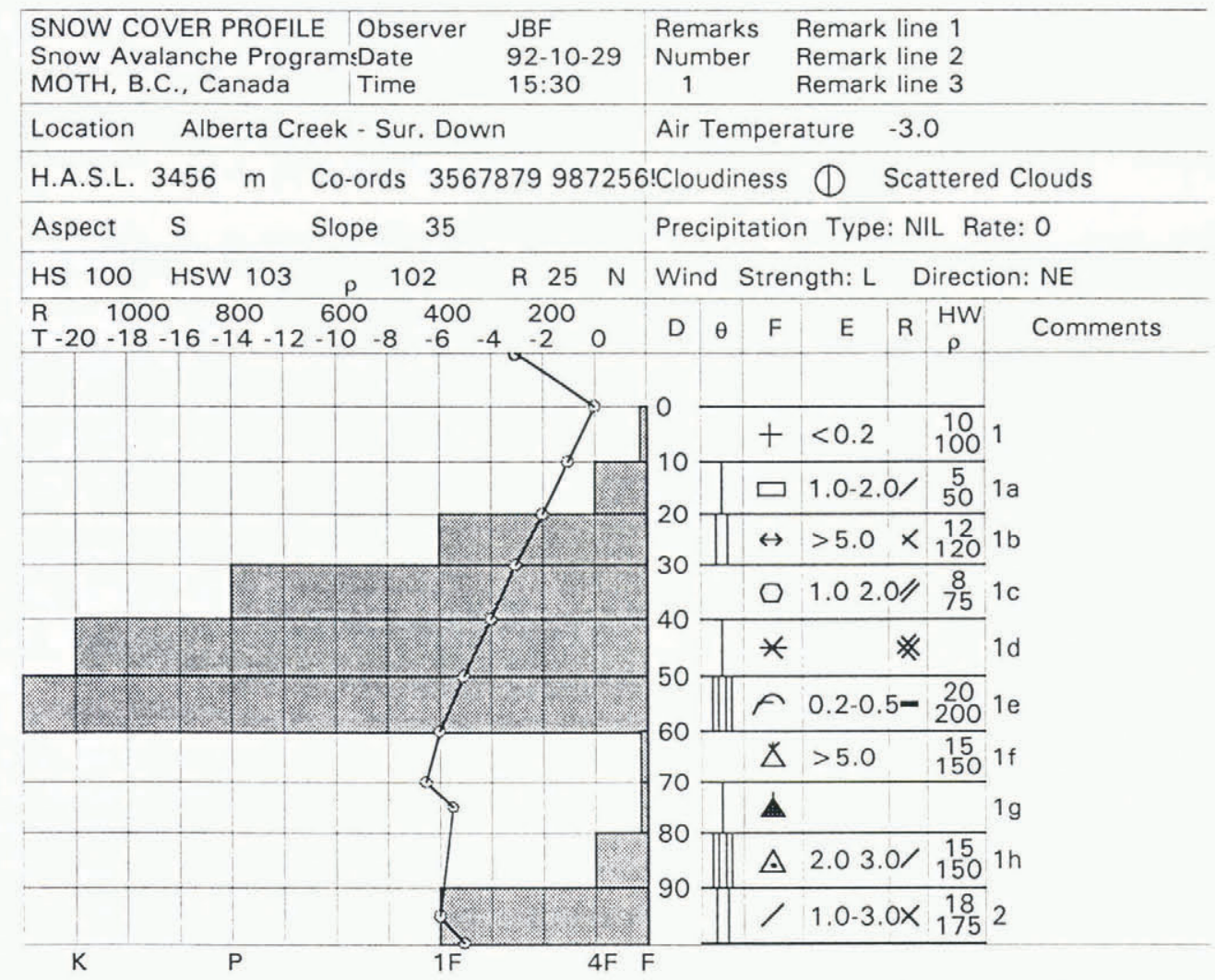

Fig. 1. Snow-pit program by Peter Weir. It runs only under the operating system Windows 3.1, conforms completely to the International Classification of Snow on the Ground, and has mouse-driven drop-down menus for the entry of most parameters.

telephone modem to other avalanche workers. The program will store and graph data on snow hardness or density, temperature, location of shears, and crystal type and the direction of metamorphism (for example small

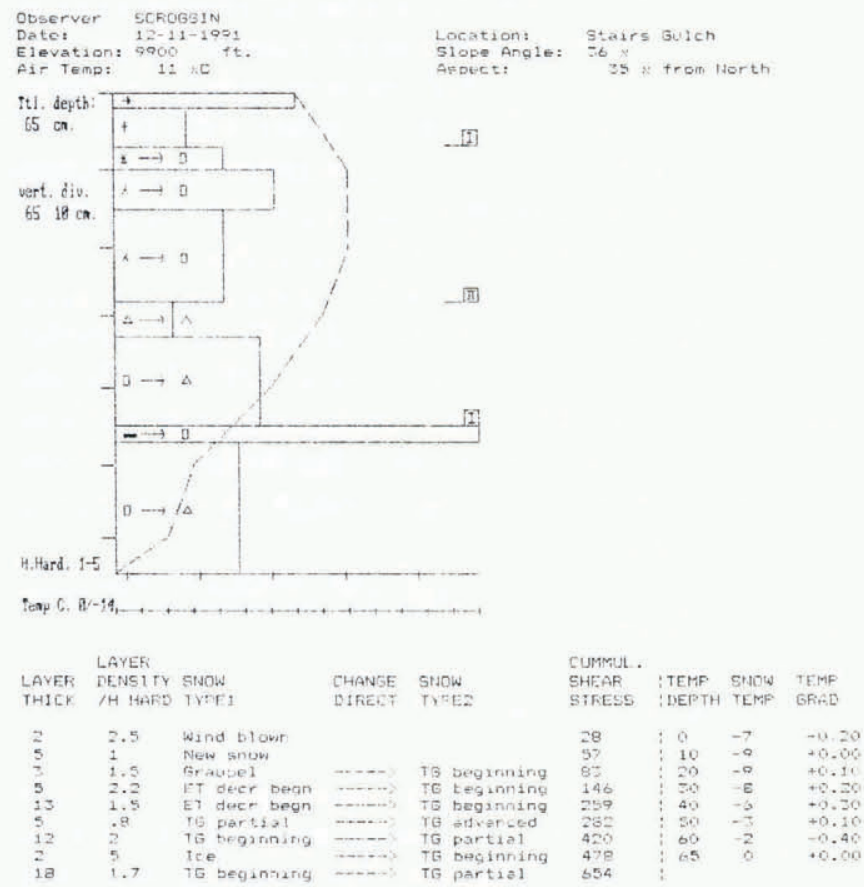

Fig. 2. Snow-pit program by Dan Judd. Blocks represent hand hardness from fist through knife. Standard snow crystal symbols represent snow crystal type within each layer. Dotted line is temperature on a scale from $0^{\circ}$ to $-14^{\circ} \mathrm{C}$. faceted grains turning into small rounded grains). As a unique feature, the program also calculates the cumulative shear stress on each layer based on the density of the overlying snow and the slope angle. In other words, if shear strength of the various weak layers is measured, one can easily calculate a stability index (strength divided by stress). It also gives a numerical calculation of temperature gradient between each layer (Fig. 2). It is available free of charge by writing to Judd (see below for addresses).

\section{Randy Trover snow-pit program}

The snow-pit program written in Pascal by $\mathrm{R}$. Trover of the Snowbird Ski Patrol differs from all the above in that it is a database of snow-pit information. In other words, it not only allows the user to query snow-pit data (for example search by date, location, depth, etc.) but it will also graph three profiles on the same page for comparison (Fig. 3). This has obvious advantages for operational use but it is not presently possible to transmit a single profile through a modem to another computer without transferring the entire database.

The program accepts and graphs the parameters of snow hardness, crystal type and temperature. At present, it does not graph snow moisture but this feature will be added to future versions. It is free of charge by contacting Trover.

\section{Roger Atkins snowpit program}

R. Atkins, also a Utah computer programmer, has 

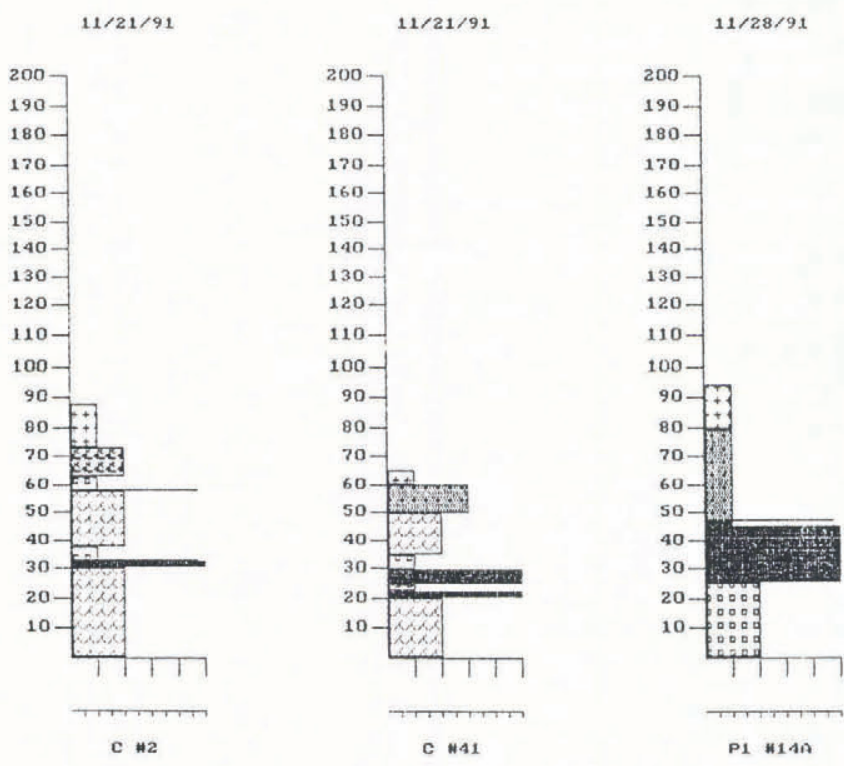

Fig. 3. Snow-pit program by Randy Trover. These are plotted without temperature data. This program is a database of snowpits. Three snowpits can be graphed together on the same screen for comparison.

written a very sophisticated snow-pit program which is normally linked to a larger comprehensive database (described below), however, he will sell it separately for around $\$ 150.00$. Like Trover's program, it is a database of snow-pit profiles; however, it can export a specific profile to a file which can be sent over a modem to another worker. It has the same query abilities as Trover's program (search by date, location, etc.), but the user can customize the program to an unlimited number of parameters that can be added or subtracted without destroying all previous data (Fig. 4).

\section{AUTOMATED SNOWPACK PROBES}

Avalanche workers have always wished for a probe which they could simply insert into the snowpack, thereby bypassing the more time-consuming conventional snow pit. Japanese researchers (personal communication from A. Abe-Ouchi) have come one step closer. They have designed a probe which simultaneously measures snow hardness (using a load cell), temperature, snow moisture (using a dielectric measurement) and reflectivity of laser light (Fig. 5). A number of different profiles are stored on a portable data-logger and then uploaded to a conventional computer back in the office.

Because snowpack properties vary, sometimes drastically, across an avalanche starting zone, a probe such as this would allow avalanche workers to map an avalanche starting zone to determine the aerial pattern of buried weak-layers. This could not only determine if a slope is unstable, but determine the optimum explosive placement for avalanche control.

We hope that this type of research continues and that one day automated snowpack probes will be lightweight, portable and inexpensive. Ideally, they would accurately measure snow strength in various layers with a high resolution, snow temperature, crystal type and water content. An instrument like this would be a revolutionary innovation for avalanche forecasters.

\section{DATABASE PROGRAMS}

One of the first uses for computers in avalanche forecasting was as a database for avalanche and weather information. For instance, they have been used in Europe for some time (Buser and others, 1987) and especially in France, e.g. Model la Plagne (Navarre and others, 1987) and AIPRA (Castets and others, 1984). These programs store data on weather, avalanches, snowpack, or any other pertinent information. They have two uses: first to graph the data for easier visualization of the critical parameters; and second, to search previous data for critical precursor patterns to avalanche activity.

Nearly any modern database software can handle this type of problem. However, because of the complex interrelationships between the parameters, and the large numbers of parameters, customization of the database using its programming language is almost always required to create a useful application. This task is quite daunting for a casual user, but several American programmers have taken on the task.

\section{Dan Judd program}

Judd has adapted the Paradox database program both by customizing the standard application and by writing specific code in the Paradox programming language. The program uses customized user-entry screens specifically adapted to data most often used by American avalanche workers. It is set up for easy queries of past data and is pre-configured for graphical display of both weather and avalanche data. One can display weather and avalanche data on any time scale from a seasonal history chart to graphing weather parameters within a specific storm (Fig. $6)$. The program also directly imports hourly data from automated stations. The storm report calculates and graphs a number of useful parameters including settlement rates within both the new and old snow, and the cumulative snow and precipitation amounts.

Since this program runs within a standard database program (Paradox) the user can modify and customize the program to serve his individual needs. If the user wants to make changes in the layout, the menu structure or the analysis of the data he must modify the source code of the Paradox programming language, which Judd will provide upon request.

The program (with a run-time version of Paradox) sells for $\$ 150.00$.

\section{Roger Atkins program}

The disadvantage of using standardized database programs is that they must operate within the limitations of the development software. For this reason, many programmers have chosen to write their own software. The most sophisticated of these customized database programs was written and tested over the past several years by R. Atkins. The program, written in Pascal, is a complete database of weather, avalanche, snowpack and 


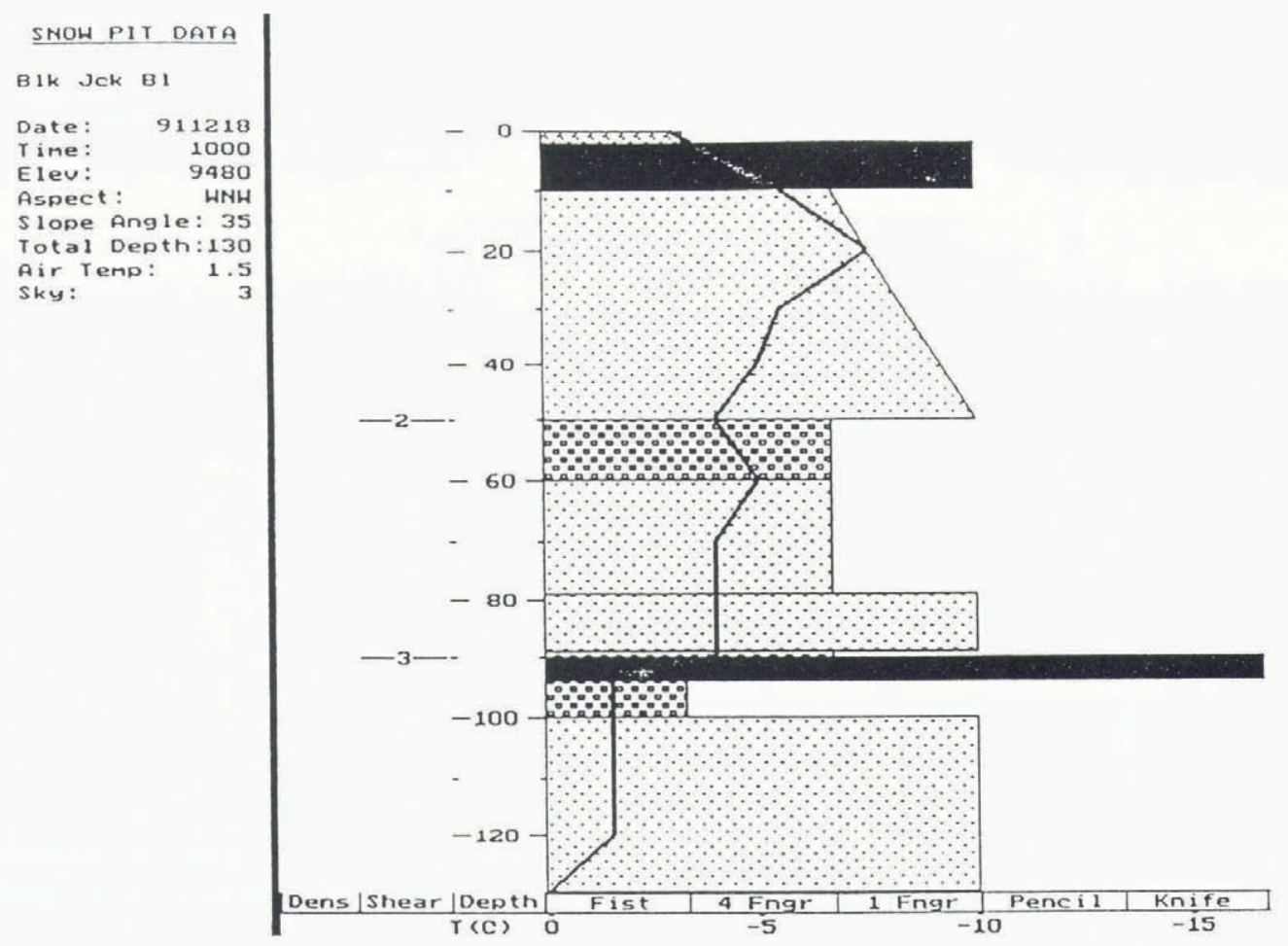

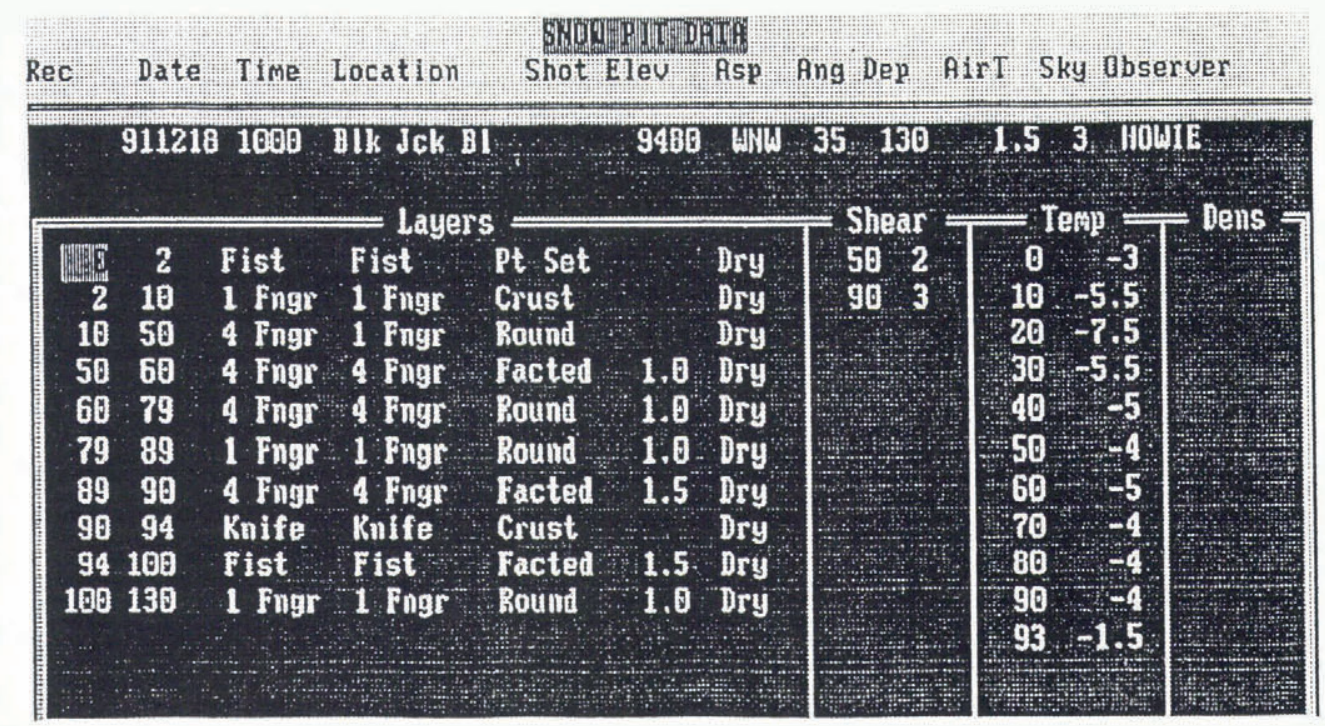

Fig. 4. Snow-pit program by Roger Atkins. This is also a database of snowpit data. The report generates a graph plus a table of data; users can configure the graph to fit their own needs.

even operational data. It is a very powerful and flexible program offering a well thought-out design. It was originally created for a large Canadian helicopter-skiing concession to keep track of several different mountain ranges and several sub-areas within each range. Therefore the program will handle multiple geographical areas simultaneously, each with several different study plots, automated weather stations, hasty snow-pit profiles, and operational data such as closures or avalanche control measures. It also directly accepts hourly data from automated weather stations, but only through a standardized input format; the user must reconfigure the data into the standardized format.

The program sells, complete with the snow-pit section, for around $\$ 500.00$.

\section{OTHER GUSTOMIZED DATABASE PROGRAMS}

Other database programs of note which use customized, proprietary programs include two developed by Snowbird and Jackson Hole. Neither of these programs is for sale, but they represent what is possible by developing a customized system. The Snowbird program, for instance, was written in the dBase programming language. Some of its idiosyncrasies include assigning a storm number for each consecutive storm throughout the season, so that both avalanches or weather can be queried by storm. They divide their mountain into zones - uncompacted, compacted, above treeline or below, and also by aspect. Each avalanche path (or shot point) has a terrain file which describes its aspect, configuration, vertical fall, etc. 
$R(\%)$

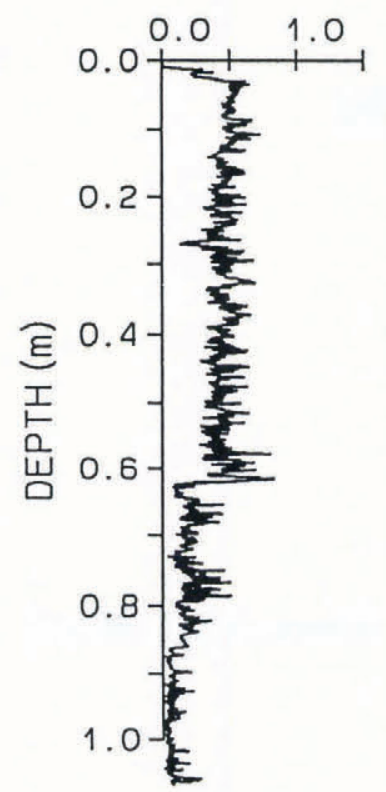

$F(N)$

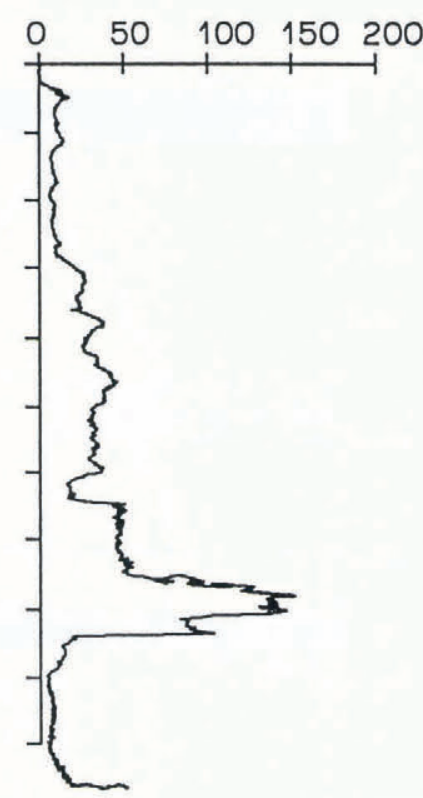

$E(1 / k \Omega)$

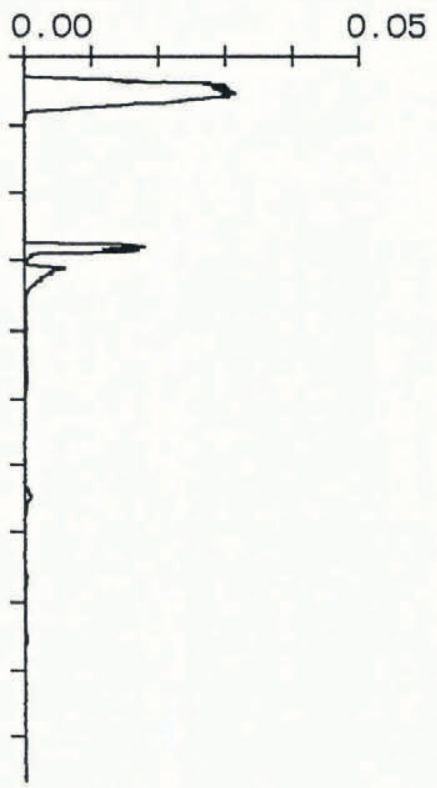

Fig. 5. Graphical output from an automated snow probe by Abe-Ouchi and others (personal communication). $R$, reflectivity of laser light; $F$, resistance to penetration of a ramonsonde cone; $E$, snow moisture as measured by dielectric resistance of the snow.

Jackson Hole ski area is unique in that they use an Apple MacIntosh computer system, and use standardized database programs written for MacIntosh. We feel that there is certainly nothing wrong with other users developing highly customized programs like these, in fact it encourages innovative ways of looking at an old problem. However, the programmers should be careful to design the programs with an ability to export data into a standardized form to be shared by other users or uploaded onto a network.

\section{NEAREST-NEIGHBORS PROGRAM}

Othmar Buser and others, from the Swiss Institute of Snow and Avalanche Research in Davos, Switzerland, wrote a program in the mid-1980s which is similar to the other database programs except that when doing a query, it calculates the closeness of fit between the present day and any past similar days (Buser and others, 1987). For instance, after entering the weather and snowpack data for the present day, it will not only find all days in the past with similar conditions, but it will rank them on how closely the conditions resemble the present day. The initial important variables were chosen statistically by doing a stepwise linear discrimination analysis on all the available parameters. Using this subset of parameters, each past day can be plotted on a multi-dimensional vectorspace. Then the Euclidian distance to each of the various points represents the closeness of fit.

Although the original program was written in German, it has recently been translated into English, and is available to all users by contacting Buser.

One possible disadvantage of the nearest-neighbors program comes from an inherent property of the statistical methods used, in that they must assume that none of the variables is intercorrelated. At present, D. McClung of the University of British Columbia in
Canada is attempting to improve on the program by using Baysian parametric discriminant analysis of the data. This may improve the accuracy of the program as it accounts for the intercorrelation of the parameters and it can also specify the probability that a given data belongs to an avalanche day or a non-avalanche day. Finally, McClung hopes to improve the accuracy further by attaching an expert system in which the forecaster can include his own estimate of the probability.

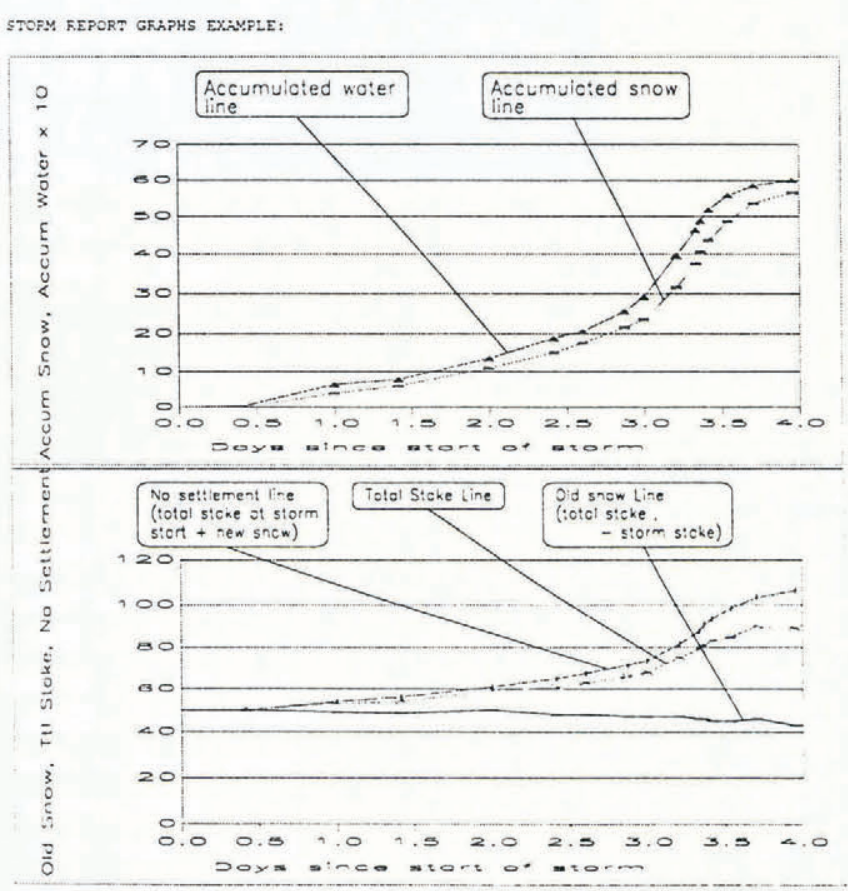

Fig. 6. A sample storm report from Judd's database program. A unique feature allows the user to see the settlement rate not only within the new snow, but within the old snow as well. 


\section{DETERMINISTIC MODELING OF THE SNOW- PACK}

\section{CROCUS}

Perhaps the most powerful computer tool in forecasting avalanches is also one of the most difficult to create modeling of the snowpack as a function of weather conditions. A team of French researchers at the Centre d'Etudes de la Neige has created a very powerful computer program, CROCUS, which simulates the evolution of a snowpack as a function of weather conditions (Brun and others, 1992). Using previous studies on metamorphism and heat flow through a snowpack as well as their own research, they have created a computer model which simulates various aspects of snow evolution throughout the season, including settlement, crystal types, temperature profile and liquid-water content. In tests of the model, even without recalibration during operation, it very accurately simulated the evolution of the snowpack throughout the season.

The input parameters are measured each hour and include air temperature, humidity, wind velocity, incoming short-wave and long-wave radiation, liquid and solid precipitation. Output parameters include total snow depth, snowpack-temperature profile, crystal types and sizes, and free water content. The French would like to use this model eventually to simulate snowpack evolution on a regional scale - to model all aspects and locations in the French Alps. To do so, they must monitor a number of automated weather stations and add some meteorological variables.

S. Ferguson and M. Moore from the Northwest Avalanche Center in Seattle are working with an English-language version of the model and attempting to add meteorological parameters to it. This type of modeling has obvious advantages not only in forecasting avalanche hazards for large areas, but also for simulating the melting of the snowpack each spring. The program is not for sale but can be made available for collaborative testing. Contact E. Brun for details.

\section{The Swiss model}

Gubler and Bader (1989) developed a computer model using air temperature and precipitation to simulate the snowpack-settling strain rate, density, temperature profile, snow surface temperature and, finally, stability. It was designed to model initial failure of slab avalanches within new snow. It does not take into account metamorphism of the snow. This model, although a preliminary one, is an important step in developing an accurate, regional-scale model of snow stability based on weather conditions. We hope that in the future, the best aspects of both the French and Swiss computer models can be combined into a useful computer tool for the practicing avalanche hazard forecaster.

\section{COMPUTER BULLETIN BOARDS OF AVALANCHE INFORMATION}

Despite our best efforts at avalanche hazard forecasting, the best indicator of avalanche activity is other avalanche activity. Therefore, sharing of avalanche occurrence information with other avalanche workers can often keep surprises to a minimum. Computer bulletin boards of current avalanche and weather information serve three locations in North America: in the Washington-Oregon area, in the Utah-Wyoming-Montana area, and finally, in western Canada.

In the Utah system, for instance, users can call into a central Novell network, log on, exchange electronic mail, exchange snowpit profiles, receive a detailed mountain weather forecast and download weather maps and satellite images to be displayed on the users' remote computers. The Utah Avalanche Forecast Center keeps track of avalanche activity and will attach a special avalanche-occurrence section to the weather forecast whenever there is unusual avalanche activity. Avalanche forecasts, warnings and any unusual avalanche activity is also broadcast over the Forest Service Data General computer network.

One of the largest problems in the United States is the standardization of data - what data to collect, how to collect it and in what format to exchange with other computers. Formally, the Forest Service had standardized data format, but since the Forest Service has given up much of its leadership position in avalanche forecasting and control, each ski area and each highway control team has slowly evolved their own unique systems. The Canadian Avalanche Association plans on meeting to resolve this problem with standardized data formats. We hope that the U.S. will adopt their lead and thereby open the door for a real-time national or international computer network of avalanche and mountain weather data.

\section{List of addresses}

Roger Atkins

7729 South 3500 East

Salt Lake City, UT 84121

U.S.A.

Eric Brun

Centre d'Etudes de la Neige

1441 rue de la Piscine

Domaine Universitaire

38406 St. Martin d'Hères

France

Dan Judd

2525 East Evergreen Avenue

Salt Lake City, UT 84109

U.S.A.

Othmar Buser or Hans Gubler

Federal Institute for Snow and Avalanche Research

CH 7260 Weissfluhjoch

Davos

Switzerland 
Randy Trover

Snowbird Ski Patrol

Snowbird, UT 84092

U.S.A.

Peter Weir

Snow and Avalanche Section

Ministry of Highways

940 Blanchard St.

Victoria, B.C. V8W 3E6

Canada

\section{REFERENGES}

Brun, E., P. David, M. Sudul and G. Brunot. 1992. A numerical model to simulate snow-cover stratigraphy for operational avalanche forecasting. 7. Glaciol., 38(128), 13-22.

Buser, O., M. Bütler and W. Good. 1987. Avalanche forecast by the nearest neighbour method. International Association of Hydrological Sciences Publication 162 (Sym- posium at Davos 1986 - Avalanche Formation, Movement and Effects), 557-569.

Castets, P., E. Devillaz, J. L. Dumas, J. P. MacVeigh, D. Marbouty and E. Pougatch. 1984. Un système automatisé de collecte et de traitement des données nivométéorologiques. Houille Blanche, 1984(6-7), 459464.

Colbeck, S. C. and 7 others. 1990. The international classification for seasonal snow on the ground. Wallingford, Oxfordshire, International Association of Scientific Hydrology. International Commission on Snow and Ice.

Gubler, H. and H. P. Bader. 1989. A model of initial failure in slab-avalanche release. Ann. Glaciol., 13, 9095.

Navarre, J. P., G. Guyomarc'h and G. Giraud. 1987. Un modèle statistique pour la prévision locale des avalanches. International Association of Hydrological Sciences 162 (Symposium at Davos 1986 - Avalanche Formation, Movement and Effects), 571-580.

The accuracy of references in the text and in this list is the responsibility of the authors, to whom queries should be addressed. 